\title{
The Functions and Driving Mechanisms of Research Universities in Regional Innovation
}

\author{
Xiaoqiang Feng \\ School of Education, Tianjin University \\ Tianjin 300354
}

\begin{abstract}
The outstanding contributions that Research universities made to regional innovation make them an indispensable part in regional innovation. Therefore, this paper analyzes the changes of role played by research universities in regional innovation from invisible interaction to leading and guidance, elaborates the influence that research universities have on regional innovation when it comes to the "input" parts such as talent cultivation, knowledge production, technology innovation, innovation and entrepreneurship education and practice as well as the "output" parts such as technology services and applications, intellectual property rights transfer and information resource sharing, summarizes various driving mechanisms such as transformation, feedback and guarantee provided by research universities to ensure the smooth operation of regional innovation so as to accumulate power for regional innovation led by research universities in China.
\end{abstract}

Keywords-Research Universities; Regional Innovation; Function; Driving Mechanism

\section{Changes of Role Played by Research Universities in REGIONAL INNOVATION}

\section{A. The Invisible Interaction Stage}

Since the inception, research universities have been committed to expanding knowledge fields and developing research styles, emphasizing that universities should contribute to the inner development of science and promote the inheritance and innovation of traditional knowledge and humanities. Starting from the 19th century, various breakthroughs have been made in the field of natural sciences under the impetus of Industrial Revolution and the strengthening of construction of science and technology systems. The research function of universities has been highlighted and various disciplines have been shaped and developed [1]. Although there was no direct interaction in innovation between research universities and regions at that time, universities indirectly provided strong driving force and support for regional development by knowledge teaching, talent cultivation and continuous supply of talents to the industrial community and society. It is precisely because of the continuous developing and appearing of the role played by talents in the industrial structure that research universities have gradually increased their status in the region.

\section{B. The Cooperation and Participation Stage}

After the internal-expansion development, Research universities have gradually developed into a symbol of the knowledge, human resources and even economic strength of a country, taking the priority in terms of government resources allocation and winning even higher reputation than peer universities. During different phases such as World War II, the Cold War and the Post-cold War period, research universities highlighted their roles, played an important part in national defense, aerospace, informatization and other technological inventions and creations and demonstrated their social service functions. In 1980, the Bayh Dole Act was formulated in the United States where the form of laws was taken to guarantee the smooth transformation of the intellectual property rights of universities' research projects to businesses. It was actually a landmark act showing research universities' participation in regional innovation. Various models such as school-enterprise cooperation, production-school-research collaboration could be found in universities to establish relations with the industrial circle and participate in regional innovation and development through project cooperation, research and development alliances, contracted research and others. This stage showed more of a chain state where the government took the leading role, industrial enterprises within the region imitatively took action and research universities made positive responses. Research universities showed unprecedented explicit and implicit power in regional innovation.

\section{The leading and guidance stage}

A diversified and systematic innovation system was gradually established in research universities through resources acquisition and communication during the cooperation period, which made them consistently maintain the top of higher education. In 1998, the United Nations Educational, Scientific, and Cultural Organization (UNESCO) issued World Declaration On Higher Education for The Twenty-first Century: Vision and Action, calling on universities to stay proactive, strengthen innovative thinking, entrepreneurial spirit and entrepreneurial spirit on the basis of the original conditions, promote the transformation of universities, conduct innovation and entrepreneurship education and establish entrepreneurial universities [2]. Research universities bore the brunt of this important role and played a significant role in domestic and foreign communication, activation of government and industrial 
innovation and changes of their internal structures and functions. Entering the 21st century, research universities have entered the core position in society with characteristics such as a large number of academic and scientific masters, outstanding scientific research achievements and abundant research funding. Therefore, research universities were more likely to spillover effects such as knowledge diffusion, innovation demonstration and so on, make radiation effects to the government, enterprises and other innovative entities, change from follow-up innovation to leading innovation and become a leader of regional innovative economic development.

\section{EFFECTIVE SEGMENTS OF RESEARCH UNIVERSITIES IN REGIONAL INNOVATION}

It is a must to rely on the internal input and output segments of research universities to implement regional innovation strategies. Only by strict control and efficient use of the input and output of research universities in guiding regional innovation can be possible to give full play to the roles played by research universities in regional innovation to achieve efficient integration of input capital and high-quality output.

\section{A. Input segments}

The input segments mainly refers to the various accumulation of strength made by research universities for regional innovation and development, which means various universities transform implicit resources into explicit technical skills and intelligence.

\section{1)Talent cultivation}

Research universities take the cultivation of innovative talents as their major task. They are committed to cultivating outstanding academic talents with theoretical innovation and high-quality talents with technological innovation. To a certain extent, the quality and quantity of talents demonstrate development status of regional scientific research and innovation. These universities are home to a large number of researchers, engineering technicians, scientific management personnel and scientific consultants and those innovative talents are the basic guarantee for the ultimate realization of knowledge diffusion and innovation performance in the region and the country.

\section{2) Knowledge Production}

There are a large number of disciplines and majors set up in research universities, while at the same time, attract senior scholars and experts of different fields, making it possible to achieve knowledge production, continuously strengthen existing knowledge structure, discover and expand new areas, inspire new ideas and settle new issues through teaching, scientific research and the continuous exchanges and integration of individuals and teams. The generation of new technologies and new industries will be driven by the generation of knowledge. At the same time, the functions and nature of dissemination of knowledge in research universities make it possible that the emerging knowledge is widely communicated to students and the society, which indeed plays a very important role in regional innovation.

\section{3) Technological innovation}

Research universities are a main producing source for high-quality, high-level academic achievements and cuttingedge technologies as well as main bodies of scientific research of the country with the intensive integration of undertaking national tasks and high concentration of research results. According to statistical results of China's scientific and technical papers, the proportion taken up by universities, research institutes and enterprises in terms of paper contributions among China's annual total amount is about 43:13:1, of which research universities account for a quite high proportion in the circle of universities. ${ }^{[3]}$ Scientific and technological innovations in developed countries are also dependent on research universities. According to the 2018 Science and Engineering Indicators report released by the National Science Foundation (NSF), a total of 409,000 academic papers were published in the United States in 2016, of which those published by the academic community accounted for three quarters and research universities were also the backbone of academic community. ${ }^{[4]}$ It can be seen from above that research universities have made great contributions to scientific and technological innovation, whose scientific research achievements were of great importance.

4) Innovation and entrepreneurship education and practice

The education and practice on innovation and entrepreneurship are mainly reflected in the following two aspects. First, there is a multilevel and systematic innovation and entrepreneurship curriculum system, including theoretical courses such as Entrepreneurship Strategy and Innovation and Entrepreneurship Management, practical courses such as Entrepreneurial Marketing for Innovative Team and Cuttingedge Technology and industrial training courses such as Simulation Training and Enterprise Practical Training. ${ }^{[5]}$ Second, there is a school-student independent mutual innovation and entrepreneurship project training system. Various excellent innovation and entrepreneurship projects are set up in Research universities on the theme of regional innovation. Besides, innovation and entrepreneurship competitions in various disciplines and innovative and entrepreneurial projects involving research institutions and industries are carried out to guide students to strengthen their practical skills in innovation and entrepreneurship, improve their resistance to the market risks and accumulate capitals for successful entrepreneurship. At the level of student autonomy, the strong atmosphere of innovation and entrepreneurship in research universities makes it possible for students to spontaneously set up many free organizations, such as associations, innovation and entrepreneurship clubs, second class and so on. With spontaneous innovation and entrepreneurship education, students' enthusiasm is fully mobilized, which provides an independent platform for students to understand industrial structure and enhance innovation and entrepreneurial skills. 


\section{B. Output segments}

The output segments mainly refers to the fact that knowledge, technology and talents from research universities are used to serve the public through cooperation with the regional economic industries.

\section{1) In the field of technology services and applications}

In terms of technology services and applications, research universities mainly carry out follow-up experiments, development and applications of scientific achievements of practical value to form new products, processes, materials and develop into new industries. Inside these universities, such transformation is achieved in two major forms, the results converter and university science parks. There are scientific research results converters set up in research universities, where specialized organizations and management personnel realize marketization of matured research results through converters. On the other hand, university science parks mange to gather together the innovative theories, products, technologies and others of research universities and build platforms for industrial cooperation, giving life to the scientific achievements in the universities, promoting the continuous development and innovation of talents and scientific research and forming clusters of special industries at the same time, which makes the university talents and technology sources constantly flow in and maximize the output results.

\section{2) In the field of intellectual property transfer.}

Intellectual property refers to the intellectual achievements or knowledge products made by universities in terms of theoretical innovation, technological innovation and other fields. It is an invisible property mainly obtained in two forms, project cooperation and establishment of enterprises. Project cooperation is an intellectual property transfer mode established by research universities, industrial circles and research institutions. ${ }^{[6]}$ Research universities reach consensus with enterprises through school-enterprise cooperation, production-study-research cooperation mechanism, which work together to develop cooperative agreements under common interest to jointly contribute to research in a certain area, which is conducive to not only transferring the implicit and explicit knowledge but also promoting knowledge innovation of enterprises. The other form is establishment of companies, because derived and new companies in research universities are also important ways of knowledge transfer in research universities. The innovation and entrepreneurship education mentioned in the previous section is an important source of driving force to promote derived companies in universities. Through the acquisition of technology licenses and allocation of intellectual property inside the research universities, new companies are set up to successfully achieve online production of innovative technologies and products and promote the development of regional innovative economy. In addition, publication of academic journals, seminars and cross-industry exchange conferences are also approaches of transferring intellectual property rights. Such approaches will export all kinds of innovative elements accumulated in research universities into different regions and bring endless possibilities for regional innovation and development.

\section{3) In the field of information sharing}

Books, periodicals, electronic literature and other resources in research universities are highly professional, scientific and authoritative, making them the mainstream of information resources in the region. Research universities actively build platforms for exchange with industries and help the industrial circle upgrade their existing technologies and products, which is the origin of ideas on the rise of new industries. The construction of regional information sharing platforms includes online resources with subject characteristics, expert consulting, scientific research achievement conversion and industry literature search systems.

\section{DRIVING MECHANISM OF RESEARCH UNIVERSITIES IN REGIONAL INNOVATION}

The smooth operation and outstanding results of the internal "input" and "output" segments in research universities are guaranteed under various driving mechanisms such as conversion mechanism, feedback mechanism and guarantee mechanism to jointly promote interaction and development between research universities and regions with mutual coordination of all mechanisms.

\section{A. Conversion Mechanism}

The conversion mechanism refers to the mechanism in which research universities participate in regional innovation, cooperates with various types of innovative subjects and transform their innovation results into practical productivity. In research universities, specialized Technology Transfer Office, Society and Science Department and other agencies are set up to be responsible for the conversion of various achievements, exporting innovation factors into the selfproduction industry and outsourcing production industry and actively exploring new approaches to ensure the most scientific, rapid and effective results conversion. In addition, there are professionals distributed in different departments in the research universities, who are responsible for relevant matters of results conversion and the provision of the most professional guidance for the conversion of innovation results in various research fields.

\section{B. Feedback Mechanism}

The feedback mechanism is an important mechanism for research universities to efficiently participate in regional innovation and ensure a sound development of the region. Each year the innovation performance evaluation is carried out in research universities to evaluate the relative efficiency between input and output, measure the resource allocation and utilization of a university, identify problems according to the evaluation results and improve the programs for research universities' participation in regional innovation in order to bring clearer follow-up direction of development. Besides, the innovation and entrepreneurship performance is also the best feedback for the outcomes of research universities' participation in regional innovation and their operation modes and development status are the best evidence ${ }^{[7]}$. It plays a vital role in the concept innovation, system improvement and platform construction of innovation and entrepreneurship education in universities and also provides reference for 
follow-up entrepreneurs. Furthermore, the high-level talents sent by the research universities to various industries in the region will return to their old school each year in the form of alumni symposiums and experience exchanges. They bring the latest information on development demands and industrial patterns in regional innovation to help the universities update curriculum system, change teaching methods and perfect talent training models.

\section{Guarantee Mechanism}

The guarantee mechanism is the key mechanism through which research universities play a role in regional innovation, ensure the smooth input and output of innovation factors within and strengthen the monitoring of the quantity and quality of results. First of all, national policies and regulations are the key. For example, Several Opinions on Deepening the Reform of Institutional Mechanisms and Accelerating the Implementation of Innovation-Driven Development Strategies released by the CPC Central Committee and State Council in 2015 provides institutional support for universities' accumulation of innovation achievements and output, controls the general direction of development paths of research universities and modes of their participation in regional innovation and enable other innovative entities in the region to share benefits and achieve win-win situation. In addition, research universities manage to formulate detailed rules and regulations consistent with their own development characteristics while closely following national policies, such as the proportion of capital allocation, construction of laboratories and research bases, rationality of teacher qualifications, cutting-edge curriculum and detailed indicators of input and output different types of innovation factors. The sophistication of these rules and regulations directly determine whether research universities can continue to supply power in regional innovation and spread the intellectual resources.

\section{CONCLUSION}

With the arrival of the knowledge economy era and global innovation competition, research universities have shown increasingly important role and status in regional innovation. In this paper, the author analyzes the change of role played by research universities in regional innovation since their inception, elaborates in combination with the effective segments of research universities in regional innovation and summarizes the driving mechanisms through which research universities give full play of their role. Although China's research universities are still in the stage of cooperation and participation in regional innovation, the day when research universities become leaders of regional innovation with their strong intellectual resources is just around the corner.

\section{REFERENCES}

[1] Qiu Yanjun. Historical Evolution and Strategic Enlightenment of the Internationalization of Research Universities in Chinese [J].Research on Higher Education in China, 2009(07).

[2] The World Conference on Higher Education. World Declaration on Higher Education for the Twenty-First Century: Vision and Action [R]. Paris France, 1998.10.09.

[3] Zhang Qian. The Number of Basic Scientific Research Papers in China Doubled in Chinese [N]. China Youth Daily, 2017(9).

[4] National Science Foundation. Science \& Engineering Indicators 2018[EB/OL].https://nsf.gov/statistics/2018/nsb20181/,2018-01-15.

[5] Yu Xiaoxiao, Liu Yuanhao. Research and Practice of Innovation and Entrepreneurship Education Mode in Research Universities Based on the Triple Helix Framework in Chinese [J].Tsinghua Journal of Education, 2016(05).

[6] Chen yun, He Yuanqiong, Zhou Zhenhong. Research on the Construction of Regional Innovation Ecosystem Leaded by Research Universities in Chinese [J]. Science \& Technology Progress and Policy, 2013(14).

[7] Guo Hong. Research on the Framework of Entrepreneurial Universities and Regional Economy Interactive Development in Chinese [J]. Journal of Anhui University of Technology (Social Sciences), 2013(01). 